\title{
Evaluating the Effects of Energy Standards on Industrial Competitiveness: Evidence from Iran
}

\author{
Bahareh Oryani $^{1}$, Afsaneh Shafiee ${ }^{2 *}$ \\ ${ }^{1}$ Technology Management, Economics and Policy Program, College of Engineering, Seoul National University, 1 Gwanak-ro, Gwanak-gu, Seoul, \\ 08826, Republic of Korea \\ ${ }^{2}$ Senior research fellow at Institute for Trade Studies and Research, Tehran, Iran
}

Received: 12/11/2019

Accepted: 16/01/2020

Published: 20/03/2020

\begin{abstract}
This research tends to investigate how industrial competitiveness could be affected by energy standards in case of Iran. Annual data on Competitiveness Industrial Index (CIP), Export Value Index (PX), Export Market Share (EMS), Industrial Energy Intensity (IEI), Manufacturing Price Index (MPI), and Total Factor Productivity (TFP) was used spanning the period 1990-2014. The results of the Seemingly Unrelated Regression (SUR) model confirmed the positive impact of PX, EMS, and TFP versus the negative impact of MPI, and the twofold impact of energy standards (IEI) on CPI.
\end{abstract}

Keywords: Energy's Standards, Industrial Competitiveness, Seemingly Unrelated Regression, Iran

\section{Introduction}

Standards are an essential element of the society in which we live. Indeed, they provide a general and repeatable basis for doing things, enhance the competitiveness of the country in the global market by improving the produced goods, and provided services. Moreover, it provides and facilitates access to foreign markets and businesses. Standards are a trade enhancer due to their role in decreasing the cost, and information asymmetries between the market forces (supply and demand sides), particularly in the case of Cross-Border Trade (CBT). In other words, they reduce technical barriers to trade across borders and facilitate access to the broader markets. Furthermore, it reinforces the competitiveness of companies by reducing costs and simplifying the purchase and selling of products and services, thereby contributing to economic growth and job creation (Stroyan and Brown 2012). Since the increased competition amongst developing countries in labor-intensive manufactures declines economic returns, maintaining the competitive advantages require to place more attention to the higher-quality markets and high-value goods. Globally integrated production networks, typically governed by buyers from developed nations, have raised competitiveness to the top of developing countries' policy agendas. Therefore, to meet just-in-time production schedules, countries require to produce high-quality products demanded by consumers and global supply chains and deliver them to markets (Guasch et al. 2007). Therefore, this research tends to 1 . evaluate the impact of energy standards (industrial energy intensity and total factor productivity on export price; 2 . identify the role of energy standards and manufacturing price index on export market share and 3 . investigate the effect of export price and export market share on industrial competitiveness. Generally, this paper seeks to explore the answer to these questions:

(a) How is the export value index affected by improving energy standards? (b) What is the effect of energy standards on export market share? How industrial competitiveness is influenced the export value index and export market share? The rest of the research is organized as follows. Section-2 presents the theoretical framework and proposes the industrial competitiveness framework based on the qualitycost-delivery (QCD) model. Section-3 explains the data and model. Section-4 exhibits empirical findings. Finally, the research ends up with pointing out the conclusions in Section-5.

\section{Theoretical Framework}

There are different factors to be considered to identify the determinants of competitiveness. One of the most significant theories in this way belongs to Porter's generic strategies. It describes how a company gains a competitive advantage in the market. Then, it laid stress on lower cost, differentiation, or focus. The deficiencies of this theory is that it shows possible market strategies taken by the firm (Porter 1980). Total Quality Management (TQM) includes quality in a broad sense. It covers all aspects of quality of interest to the consumer and the organization. Hence, not explicitly mention, the model combines both improving qualities, cost-cutting, and increasing productivity. The model is a good measure of evaluating the role of quality competitiveness at the organization level (and at the same time the effect of cost management to that end); however, it falls short of describing the competitiveness performance at the macro-level. Furthermore, it ignores the impact of a delivery factor (Evans 2002). The Quality - Cost - Delivery

*Corresponding author: Afsaneh Shafiee, Senior research fellow at Institute for Trade Studies and Research, Tehran, Iran. Email: a.shafiei@itsr.ir

https://doi.org/10.47277/JEEP/1(1)6 
(QCD) model is an alternative to overcome the deficiencies mentioned above. It is a "three-dimensional" model to be inter-related together. The model is popular and applies to both organizations and manufacturing activities (Fig. 1).

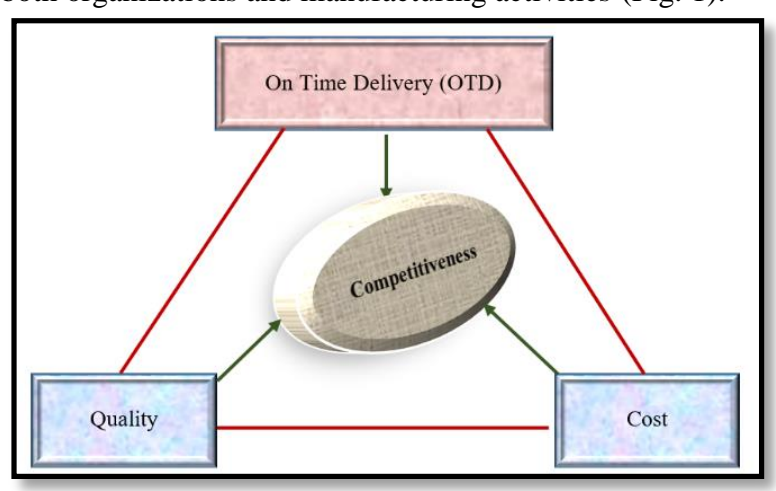

Source: (Imai 2007)

Figure 1. Quality-Cost-Delivery Model

QCD model is applied to evaluate different factors of the production process, and it could be helped policymakers to prioritize their future goals. About the cost, the higher price (cost of finished goods) results in the lower quantity demanded. Qquality could be divided into two groups: technical and appearance. Technical quality refers to product reliability (such as life cycle), while the appearance quality belongs to the visual characteristics of products like packaging design. Finally, customers will be satisfied if their perceived delivery times are shorter. This model covers essential factors of competitiveness; however, when it comes to determining factors of cost and quality competitiveness, it remains silent. To get to the determining factors of cost and quality competitiveness, the (Deloitte 2016) has developed a theoretical framework has developed a theoretical framework. The introduced industrial competitiveness model consists of 12 components (Fig. 2).

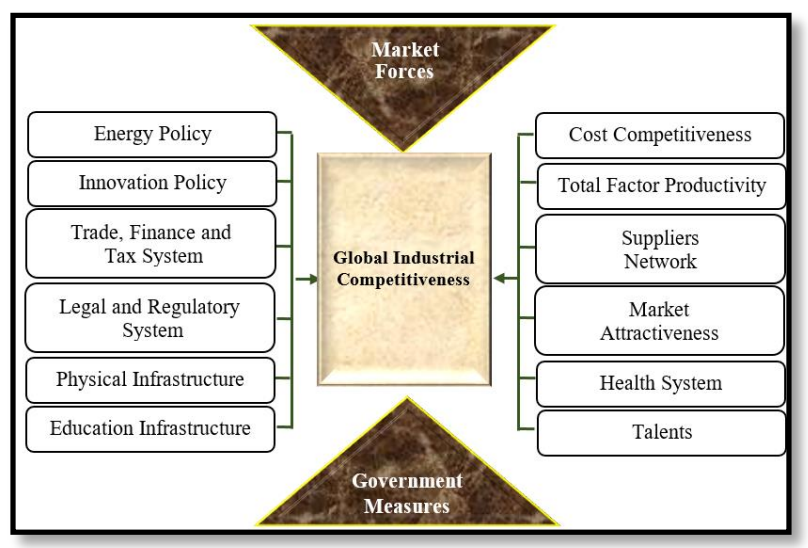

Source: (Deloitte 2016)

Figure 2. Industrial Competitiveness Model

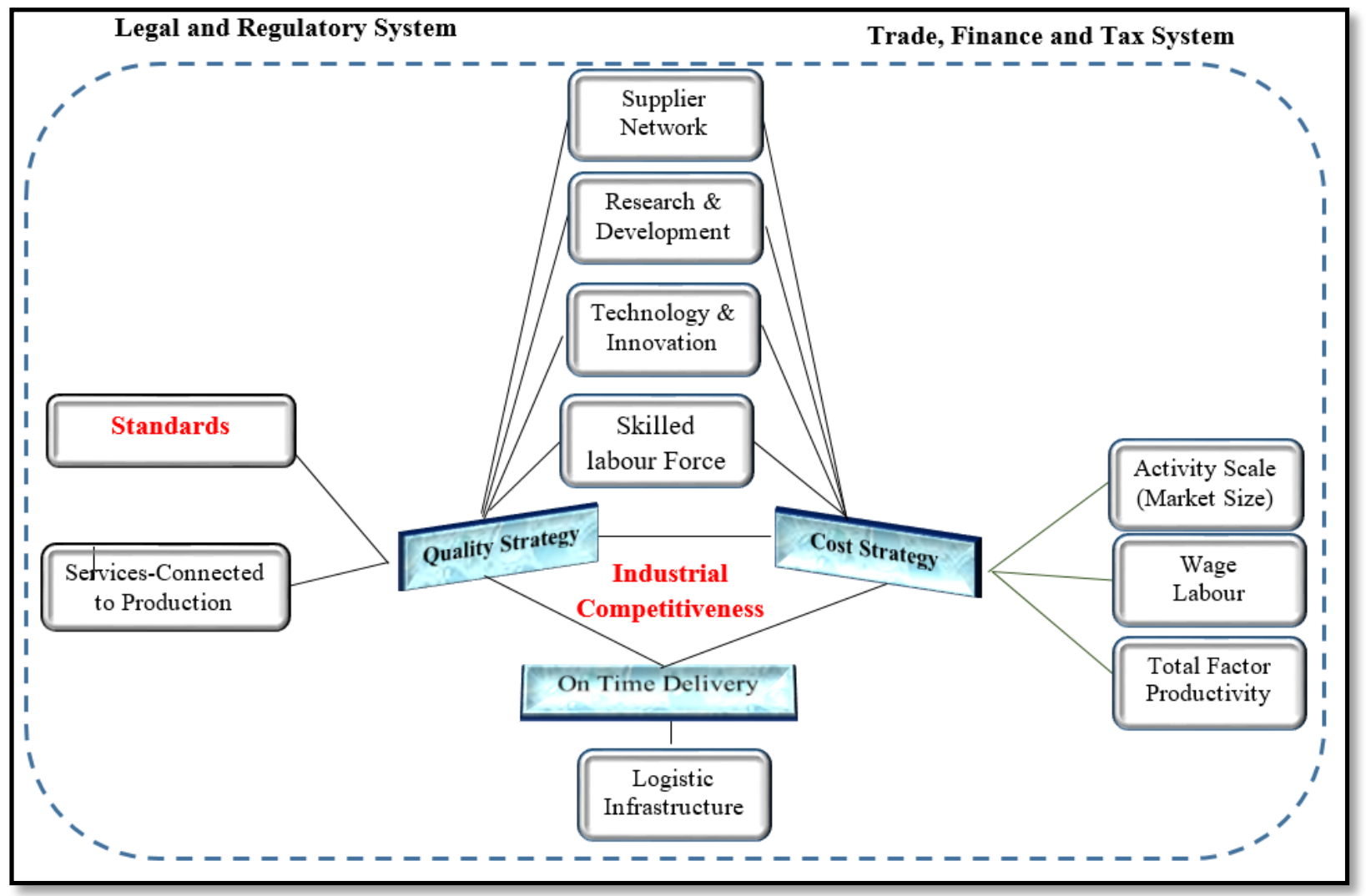

Source: developed by author from (Imai 2007), and (Deloitte 2016) 
Figure 3. Industrial Competitiveness Framework based on QCD Model

The hybrid model should be employed to achieve the goals of this research. The proposed model is a combination of the Quality-Cost-Delivery (QCD) model (Fig.1) and the industrial competitiveness model (Fig.2), which illustrated in Fig. 3. Fig 3. Industrial Competitiveness Framework based on QCD Model. Cost leadership affected by market size, wage labor, and total factor productivity. Quality leadership influenced by standards and service-connected to production. Owning supplier network, Research and Development (R\&D), technology and innovation, and the skilled labor force affecting both the abovementioned leadership factors. Being on time affected by logistic infrastructure dramatically. The legal and regulatory system, trade finance, and tax system could be considered as influential factors for the business environment. These factors can play dual roles, meaning that they can facilitate or restrict competitiveness.

\section{Data and Model}

According to the hybrid model and considering the effects of the supply network, logistic infrastructure, labor force, services connected to production as the given term, we have:

$$
\left\{\begin{array}{c}
C P I=f\left(P_{X}, E M S\right) \\
E M S=f(I E I, M P I) \\
P X=f(I E I, T F P)
\end{array}\right.
$$

where $C P I$ is competitiveness Industrial Index; $P X$ is export Value Index; $E M S$ is export Market Share; IEI is industrial Energy Intensity as a proxy of satisfying energy standards; $M P I$ is manufacturing Price Index; and TFP is total Factor Productivity. The annual data was used spanning the period of 1990-2014. The investigated variables are retrieved from different sources such as World Bank (Bank 2018), United Nations Industrial Development Organization (Portal 2020), BP statistic (Statistical Review of World Energy 2019), and Asian Productivity Organization (APO Productivity Databook 2019) and the (Cneteral Bank of the Islamic Republic of Iran). Seemingly Unrelated Regression (SUR) proposed by (Zellner 1962) was employed to estimate the systems of equations. This model is a generalized form of a linear regression model that consists of several regression equations, each having its dependent variable and potentially different sets of exogenous explanatory variables. Each equation is a valid linear regression on its own and could be estimated separately, which is the reason of calling this system as seemingly unrelated (H Greene 2012). Since the SUR method is a system approach (equations 1-3 as shown below), the model is solved with the system of simultaneous equations. It noteworthy to mention that to reduce the data variability and to avoid heteroscedasticity problem in the error terms, the data are converted to the logarithm form (Tiwari 2010).

$$
\begin{aligned}
& C P I=C_{11}+C_{12} \log _{X}+C_{13} \log E M S+\mu_{14} \\
& E M S=C_{21}+C_{22} \log I E I+C_{23} \log M P I+\mu_{24} \\
& P_{X}=C_{31}+C_{32} \log I E I+C_{33} \log T F P+\mu_{34}
\end{aligned}
$$

\section{Empirical Results}

There are several unit root tests to check the variable stationary. In this research the Dickey-Fuller-Generalized Least Squares (DF-GLS) was performed. This test developed by (Elliott, Rothenberg, and Stock 1992) as a modification of the Augmented Dickey-Fuller Test (Cheung and Lai 1995). The results of unit root tests at the level of the variables are summarized in table 1.

Table 1. The Unit root test at the level of variables (at 5\% significance level)

\begin{tabular}{ccc}
\hline \multirow{2}{*}{ Variables } & \multicolumn{2}{c}{ DF-GLS (null: variable has a unit root) } \\
\cline { 2 - 3 } & Test statistic & Critical value at level \\
\hline $\log C P I$ & -2.59 & \\
$\log P X$ & -2.01 & $-3.19^{*}$ \\
$\log E M S$ & -2.52 & \\
$\log I E I$ & -3.53 & \\
$\log M P I$ & -2.56 & \\
$\log T F P$ & -2.01 & \\
Source: (Elliott, & Rothenberg, and Stock 1992)
\end{tabular}

Source: (Elliott, Rothenberg, and Stock 1992)

As illustrated in Table 1, all variables are stationary at the level (I (0)). Therefore, the estimated model results by SUR are shown in table 2 .

Export Value Index is connected positively to the Industrial Competitiveness Index $(5.6 \%$ increase in CPI due to a $10 \%$ increase in PX). Indeed, the higher export performance, the more likely it will be to capture potential demand compared to the competitors, meaning higher competitiveness.

Export Market Share is linked positively to the CPI (a $10 \%$ increase in export market share improves CPI by about $3.3 \%$ ). In other words, a burgeoning domestic economy can increase its market share by selling higher quality goods at lower prices (two main components of competitiveness).

Energy Intensity of Industrial Index is a ratio between energy consumption in industry (including energy industry own use) and industry sector value added, which measured at purchasing power parity. Energy intensity is an indication of how much energy is used to produce one unit of economic output. The higher energy intensity indicates a higher price or cost to convert energy into an economic output and vice versa. In this study, the energy intensity of industrial index is considered as a proxy of energy standard. Therefore, it harms export market share and therefore on CPI since it increases the price or finished cost of goods or services. Empirical findings confirm that a $10 \%$ decrease in IEI boosts the CPI by about $2 \%$. While it connects positively to the export value index by raising the export unit value index. Indeed, $1.6 \%$ increase in the export value index is caused by a $10 \%$ increase in IEI.

Manufacturing Price Index_is a subset of the Producer Price Index (PPI). PPI is a group of Indices that measure the average change in selling price obtained by domestic producers over time. This index covers three ranges of production namely manufacturing/industry-based, commodity-based, and commodity-based final demand intermediate demand. As it is illustrated in table 2, there is a negative relationship between MPI and export market share, 
which can be explained by the economic theory. Based on the theory the more the price increases the more the market share (domestic and export) shrink. As shown in table 2, a
$10 \%$ increase in MPI leads to decrease in export market share by $4.8 \%$.

Table 2. The Results of SUR Method

\begin{tabular}{|c|c|c|c|c|}
\hline & Coefficient & Std. Error & $\mathrm{t}$-Statistic & Prob. \\
\hline $\mathrm{C}(11)$ & -1.550781 & 0.111192 & -13.94683 & 0.0000 \\
\hline $\mathrm{C}(12)$ & 0.557159 & 0.056216 & 9.911063 & 0.0000 \\
\hline $\mathrm{C}(13)$ & 0.321118 & 0.109449 & 2.933950 & 0.0046 \\
\hline $\mathrm{C}(21)$ & 1.250815 & 0.129487 & 9.659795 & 0.0000 \\
\hline$C(22)$ & -0.193527 & 0.030517 & -6.341586 & 0.0000 \\
\hline $\mathrm{C}(23)$ & -0.470946 & 0.096060 & -4.902639 & 0.0000 \\
\hline $\mathrm{C}(31)$ & 0.581082 & 0.165225 & 3.516911 & 0.0008 \\
\hline $\mathrm{C} \mathrm{(32)}$ & 0.156603 & 0.038156 & 4.104298 & 0.0001 \\
\hline $\mathrm{C}(33)$ & 1.993108 & 0.139172 & 14.32116 & 0.0000 \\
\hline
\end{tabular}

Determinant residual covariance

2.67E-08

Equation: LOGCPI $=\mathrm{C}(11)+\mathrm{C}(12) * \mathrm{LOGPX}+\mathrm{C}(13) * \mathrm{LOGEMS}$

R-squared

Adjusted R-squared

S.E. of regression

Durbin-Watson stat
0.825041 Mean dependent var

$-0.397200$

0.809135 S.D. dependent var

0.063867 Sum squared resid

1.730530

Equation: LOGEMS $=\mathrm{C}(21)+\mathrm{C}(22) *$ LOGIEI+C $(23) *$ LOGMPI

R-squared

Adjusted R-squared

S.E. of regression

Durbin-Watson stat
0.824101 Mean dependent var

$-0.113700$

0.808110 S.D. dependent var

0.154072

0.067491 Sum squared resid

0.100212

Equation: LOGPX $=\mathrm{C}(31)+\mathrm{C}(32) *$ LOGIEI+C (33) * LOGTFP

R-squared

Adjusted R-squared

S.E. of regression

Durbin-Watson stat
0.901267 Mean dependent var

2.136000

0.892292 S.D. dependent var

0.328988

0.107970 Sum squared resid

1.698620 
From Table 2, all coefficients are in the line with the economic theory and statistically significant. The results can be illustrated in Fig. 4 .

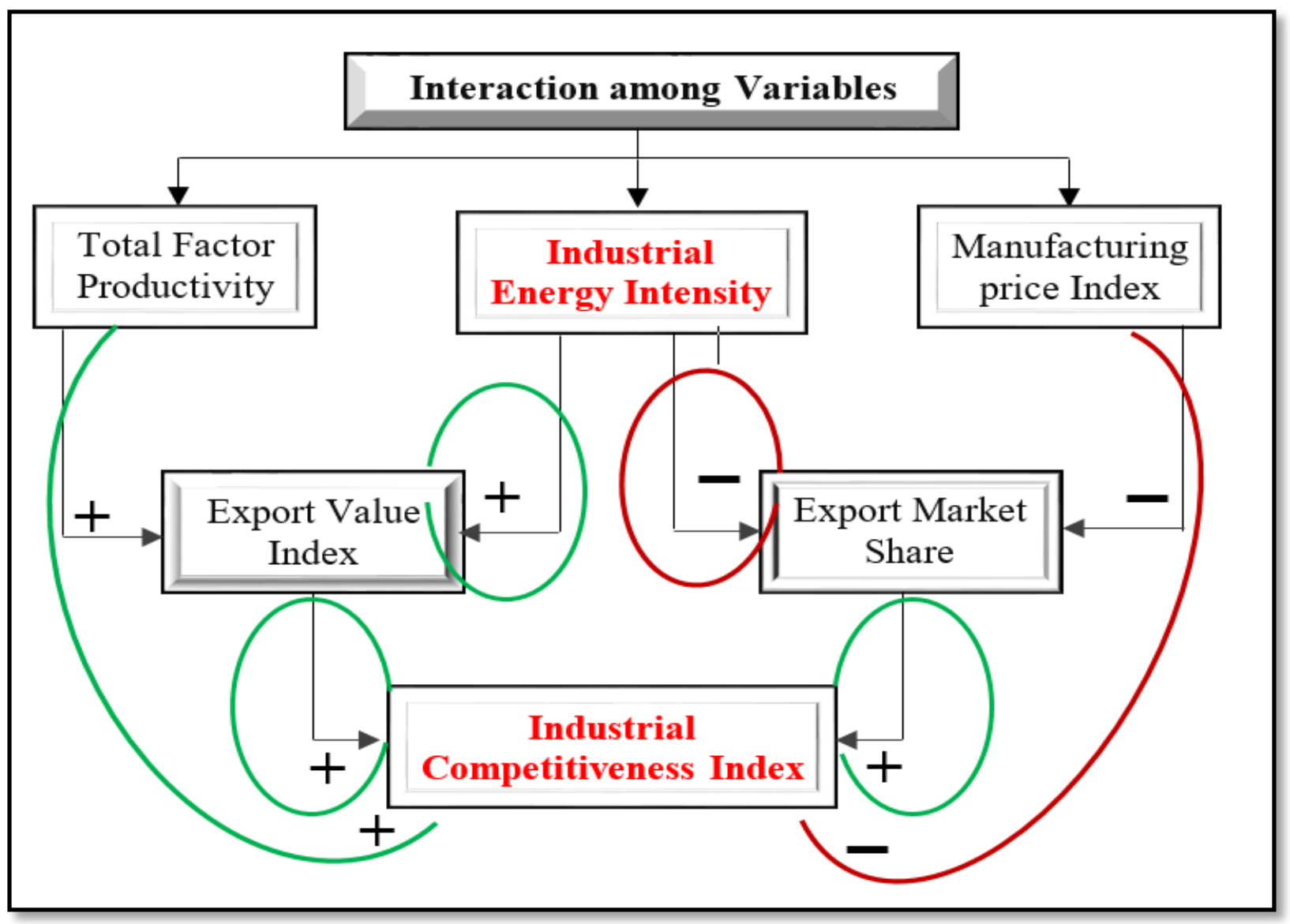

Figure 4. Interaction among Variables

Table 3. Summary of Results

\begin{tabular}{|l|l|c|}
\hline Dependent variables & Independent variables & Results \\
\hline \multirow{2}{*}{ Industrial Competitiveness Index } & Export Value Index & + \\
\cline { 2 - 3 } & Export Market Share & + \\
\hline \multirow{2}{*}{ Export Market Share } & Industrial Energy Intensity & - \\
\cline { 2 - 3 } & Manufacturing Price Index & - \\
\hline \multirow{2}{*}{ Export Value Index } & Industrial Energy Intensity & + \\
\cline { 2 - 3 } & Total Factor Productivity & + \\
\hline
\end{tabular}

Total Factor Productivity (Multifactor Productivity). This variable has a positive impact on export value index. Indeed, the greater the TFP, the more likely it will be to produce further goods and services, which enhances the export value. For $10 \%$ in TFP there will be $20 \%$ of increase in export value index. Summary of results and therefore the answer of research questions can be listed as table 3 .

\section{Conclusions}

Using SUR model, this research was conducted to evaluate the impact of industrial energy intensity and total factor productivity on export price; the role of energy standards and manufacturing price index on export market share; and the effect of export price and export market share on industrial competitiveness over period 1990 to 2014 in case of Iran. The results of unit root test demonstrated that at $5 \%$ level, all variables are co-integrated of order 0 (stationary at level). Moreover, all coefficients are in the line with the economic theory and statistically significant. From the results of the SUR model, export value index (PX), export market share (EMS), and total factor productivity (TFP) have a positive impact on industrial competitiveness index (CPI), While Manufacturing Price Index (MPI) linked negatively. Industrial energy index (IEI, as a proxy of energy standard) has a twofold impact on CPI. In one hand, it may reduce CPI through shrinking export market share, in other hands, it may improve it through raising export value index (the higher export performance, the more likely it will be to capture potential demand compared to the competitors). 


\section{References}

"APO Productivity Databook." 2019. https:/www.apotokyo.org/publications/ebooks/apo-productivity-databook2019/.

Bank, W. 2018. "Data Bank: World Development Indicators.” URL: http://databank. worldbank. org/data/source/worlddevelopment-indicators.

Cheung, Yin-Wong, and Kon S Lai. 1995. "Lag Order and Critical Values of the Augmented Dickey-Fuller Test." Journal of Business \& Economic Statistics 13(3): 277-80.

"Cneteral Bank of the Islamic Republic of Iran." https://www.cbi.ir/section/1372.aspx.

Deloitte, T C. 2016. "Global Manufacturing Competitiveness Index." Recolectado de: https://www2. deloitte. com/global/en/pages/manufacturing/articles/globalmanufacturingcompetitiveness-index. html.

Elliott, Graham, Thomas J Rothenberg, and James H Stock. 1992. Efficient Tests for an Autoregressive Unit Root. National Bureau of Economic Research Cambridge, Mass., USA.

Evans, James R. 2002. “Total Quality Management.” INFOR 40(4): 364.

Guasch, José Luís, Jean-Louis Racine, Isabel Sanchez, and Makhtar Diop. 2007. Quality Systems and Standards for a Competitive Edge. The World Bank.

H Greene, William. 2012. "Econometric Analysis."

Imai, Masaaki. 2007. “Gemba Kaizen. A Commonsense, Low-Cost Approach to Management." In Das Summa Summarum Des Management, Springer, 7-15.

Portal, UNIDO Statistics Data. 2020. "UNIDO." https://stat.unido.org/.

Porter, Michael E. 1980. "Competitive Strategy Free Press New York." PorterCompetitive Strategy 1980: 324-425.

"Statistical Review of World Energy." 2019. https://www.bp.com/en/global/corporate/energyeconomics/statistical-review-of-world-energy.html.

Stroyan, James, and Neil Brown. 2012. Using Standards to Support Growth, Competitiveness and Innovation: A Smart Guide on Promoting and Facilitating SME Competitiveness through the Development and Use of Standards with the Help of EU Structural Funds. European Union.

Tiwari, Aviral K. 2010. "Globalization and Wage Inequality: A Revisit of Empirical Evidences with New Approach.” Journal of Asian Business Management 2(1): 173-87.

Zellner, Arnold. 1962. "An Efficient Method of Estimating Seemingly Unrelated Regressions and Tests for Aggregation Bias." Journal of the American statistical Association 57(298): 348-68. 